\title{
Effects of Daily Intentional Abdominal Muscle Contraction in Pilates Participants with Real-Time Feedback on Body Composition and Trunk Stability
}

\author{
Jae-Hyeon Seong ${ }^{1^{*}}$, Chang-Beom Kim² \\ ${ }^{1}$ Department of Rehabilitation Center, Daejeon Wellness Hospital, Daejeon, Korea \\ ${ }^{2}$ Department of Physical Therapy, Daewon University, Jecheon-si, Chungcheongbuk-do, Korea
}

\author{
*Corresponding author: Jae-Hyeon Seong, \\ Department of Rehabilitation Center, \\ Daejeon Wellness Hospital, 2, 1777 beon-gil, \\ Dongseodae-ro, Daedeok-gu, Daejeon 34425, \\ Korea \\ Tel.: +821064851480 \\ Fax: +82 427128599 \\ Email:sjh2356@hanmail.net
}

Received July 14, 2017

Revised October 16, 2017

Accepted October 31, 2017

Published March 30, 2018

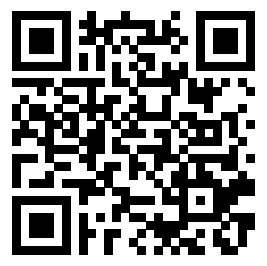

\begin{abstract}
Purpose: The purpose of this study was to provide pilates participants with realtime feedback about their intentional abdominal muscle contractions to enable them to practice these contractions in daily life. The study also investigated the effects of intentional abdominal muscle contraction accompanied by real-time feedback on body composition and trunk stability. Methods: Thirty-one pilates participants were divided into an experimental group $(n=16)$ that was provided with real-time feedback and a control group $(n=15)$ that did not receive feedback. Participants' body composition and trunk stability were evaluated before and after the experiment. Both groups performed pilates exercises over an 8-week period. Only the experimental group was provided with real-time feedback on the changes to their waist circumference. Results: During body composition evaluation, the experimental group showed statistically significant declines in weight, body mass index, body fat percentage, and waist-hip ratio, whereas the control group exhibited no statistically significant differences in any of these variables. The experimental group experienced significantly larger declines in their body fat percentage and waist-hip ratio compared with the control group. On trunk stability evaluation, the experimental group showed statistically significant increases in trunk extension, trunk flexion, and the left side bridge after the experiment, whereas the control group exhibited a statistically significant increase only in the left side bridge. There were no statistically significant between-group differences for any of the variables. Conclusion: The experimental group, which performed intentional abdominal muscle contractions with real-time feedback, showed improved body composition and trunk stability, including improved body fat percentage and waist-hip ratio. These results indicate that providing intentional abdominal muscle contraction in addition to pilates exercises could provide both physical and cosmetic benefits, assisting practitioners in providing body shape and trunk stability improvements.
\end{abstract}

Keywords: Pilates, Real-time feedback, Body composition, Trunk stability, Intentional abdominal muscle contraction

\section{Introduction}

현대사회는 문명의 발달로 인해 풍요로운 삶을 누리고 있으나 운동부족으로 인해 비만, 당뇨병, 고혈압, 고지혈증 등 대사증 후군의 유병률이 점차 높아지고 있다(KOSIS, 2017). 신체활동 의 부족은 체지방이 증가되고, 운동능력과 체력의 저하를 동반
하여 삶의 질을 떨어뜨린다(Park \& Kwon, 2011). 특히 과도한 복부비만은 미용뿐만 아니라 건강에도 나쁜 영향을 미친다. 비 만은 허리 주변근육들의 약화와 요추부의 코어근육을 사용하지 못함으로써 몸통 안정성(trunk stability)이 저하되고 만성허리 통증을 발생시킨다(Neumann, 2010). 현대인들은 신체 외적인 아름다움과 건강에 대한 관심은 높아지고 있으며 이러한 성향은 

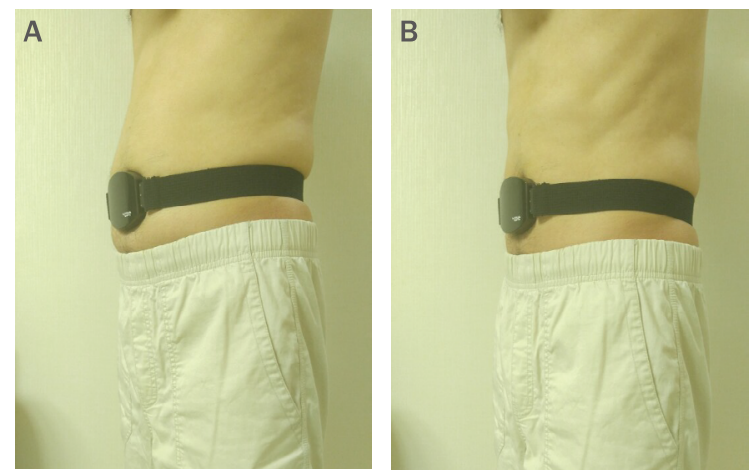

Figure 1. Picture of wearing a waist circumference sensor. (A) When the subject's waist circumference increased above the reference value because of discontinuance of intentional abdominal muscle contraction, the sensor in the main belt, which sensed the length change, was activated. Upon this activation, the main belt generated vibrations, providing feedback to help the subject perform repeat abdominal contractions. (B) If the waist circumference decreased below the reference value during abdominal contraction, the vibration stopped.

육체적 그리고 정신적인 건강을 위한 운동을 찾게 되는 동기가 되었다. 일반적으로 체지방 감소를 위해 걷기나 달리기와 같은 유산소 운동이 주로 사용되지만 흥미도가 떨어져 규칙적인 참여 가 어려운 문제점이 있다. 다양한 운동 방법 중 필라테스는 심리 적 만족감을 향상시키며 지속적인 운동 참여를 할 수 있도록 하 였다(Lee \& Yoo, 2015).

필라테스는 독일의 조셉 필라테스에 의해 1900 년대초에 개발 되어 현재까지 끊임없이 발전되고 있는 운동기법이다. 신체중심 부를 강화시키고 안정화시키는 운동으로 몸을 유연하고 균형 있 게 만들어주며, 체지방률과 복부지방률에 긍정적인 영향을 준다 고 보고하였다(Park \& Park, 2006; Segal et al., 2004). 이외 에 치료적 목적으로 약화된 허리 주변근육의 강화를 위해 동시 수축을 유도하는 특별한 몸통 안정화 운동들이 개발되어 왔다.

몸통 안정화 운동으로는 swiss ball을 이용한 등척성 운동 (isometric exercise), 교각 운동(bridging exercise), 배긴 장 방법(abdominal bracing maneuver), 배꼽당기기 방법 (abdominal hollowing maneuver) 등이 있다(Beith et al.,
2001; Mew, 2009; Urquhart et al., 2005). 이러한 운동방법 들의 효과적인 수행을 위해 다양한 생체되먹임이 제시되었다. 생체되먹임을 이용한 훈련에는 근전도 신호를 이용하는 방법, 압력계를 이용한 방법, 소리를 이용한 방법 등 다양한 실시간 생 체되먹임 방법을 이용하였다(Dozza et al., 2011; Jung et al., 2014; Nanhoe-Mahabier et al., 2012). 하지만 일반인들이 사 용하기에는 많은 비용과 인원이 필요하고 치료실 이외의 공간에 서는 적용하기 어렵다.

필라테스 프로그램에 포함된 다양한 몸통 안정화 운동은 요 추부 근육을 활성화하여 몸통 안정성을 향상시키고 에너지 소모 를 통해 지방을 감소시킨다(Segal et al., 2004). 몸통의 안정화 는 필라테스 운동뿐만 아니라 일상생활에서 다양한 과제를 하는 동안 필요하다. 하지만 몸통 안정화를 위한 요추부 근육의 활성 화는 운동 시에만 사용되었기 때문에 일상생활 중에는 적용하기 어렵다. 일상에서 과제 수행 중 요추부의 근육을 활성화하기 위 해서는 많은 오류의 감지를 통한 반복적 훈련이 필요하며 이를 통해 학습이 될 경우 자동적인 근활성 패턴으로 나타날 것이다 (Dayan \& Cohen, 2011).

본 연구의 목적은 필라테스 운동 프로그램 참여자에게 의도적 인 복근수축이 일상생활 중에도 가능하도록 생체되먹임을 제공 하여 신체조성과 몸통 안정성에 미치는 영향을 알아보고자 하였 다.

\section{Methods}

\section{1. 연구 대상}

본 연구의 대상자는 용인시에 거주하는 성인 여성 $(\mathrm{N}=31)$ 을 대상으로 하였다. 연구 대상자들은 신경계 및 근골격계 질환이 없고 연구의 목적과 의의를 충분히 이해하고 따를 수 있으며 참 여에 동의한 자로 하였다. 대상자의 일반적 특성은 두 군간 유의 한 차이가 없었다(Table 1).

\section{2. 연구 방법}

1) 실험절차 및 측정도구

본 연구는 필라테스 운동에 참여하는 성인을 무작위 선정을

Table 1. General characteristics of participants

\begin{tabular}{lcc}
\hline & $\begin{array}{c}\text { Experimental group } \\
\left(\mathrm{n}_{1}=16\right)\end{array}$ & $\begin{array}{c}\text { Control group } \\
\left(\mathrm{n}_{2}=15\right)\end{array}$ \\
Age $(\mathrm{yr})$ & $38.3 \pm 7.8^{\mathrm{a}}$ & $40.7 \pm 10.5$ \\
Height $(\mathrm{cm})$ & $163.4 \pm 3.8$ & $163.5 \pm 6.2$ \\
Weight $(\mathrm{kg})$ & $57.0 \pm 8.6$ & $58.5 \pm 8.5$ \\
$\mathrm{BMl}^{\mathrm{b}}\left(\mathrm{kg} / \mathrm{m}^{2}\right)$ & $21.3 \pm 2.9$ & $21.8 \pm 2.4$ \\
\hline
\end{tabular}

\footnotetext{
${ }^{\mathrm{a}}$ mean \pm standard deviation; ${ }^{\mathrm{b}}$ body mass index.
} 
통해 생체되먹임을 동반한 실험군과 복근수축의 중요성을 교육 받은 대조군으로 하였다. 실험 전과 후에 신체조성 측정을 위하 여 체성분 분석기(In-body 720; Biospace, Korea)를 사용하였 다. 몸통 안정성을 측정하기 위해 McGill et al. (1999)이 제시한 몸통굴곡(trunk flexion), 몸통신전(trunk extension), 양측 사 이드 브릿지(side bridge)를 실시하여 측정하였다.

실험군은 일일 $60 \mathrm{~min}$, 주 3회, 8주 동안 필라테스 운동을 실 시하였다. 또한 일상생활 중 보행과 같은 선 자세에서 복부의 이 완을 감지하여 생체되먹임을 제공하는 허리둘레 감지기를 착용 하였다. 허리둘레 감지기(Keeping Core Band 17M1-03; TCC, Korea)는 허리를 감싸는 벨트 형태의 장비로 벨트 본체와 비탄 력 밴드로 구성되어 있다(Figure 1). 연구자는 허리둘레 감지 기 착용 전 대상자에게 배꼽 당기기 방법인 '배꼽을 척추 쪽으로 1-2 cm 당기도록 배에 힘을 줄 것'을 요구하였다. 이 상태에서 본체가 배꼽 $2 \mathrm{~cm}$ 아래에 오도록 하고 벨트의 길이를 조절하여 착용하도록 교육하였다. 배꼽 당기기 방법의 동작이 어려운 경 우 누운 자세나 앉은 자세부터 시작하여 점차 선자세로 연습을 하였다. 대상자에게 숨을 참는 것과 같은 과도한 수축이 되지 않 도록 하였다.

복부근육의 수축과 이완 시 허리둘레길이 차이를 알아보기 위 해 20 명을 대상으로 예비조사를 실시하였다. 의도적인 복근수
축 시 이완되었을 때보다 평균 $1.5 \%$ 의 둘레가 감소되었으며 이 를 개인마다 센서의 기준값으로 설정하였다. 의도적인 복근수 축이 중단되어 허리둘레의 길이가 기준값 이상 늘어나면 본체에 있는 길이 감지 센서가 작동한다. 감지한 즉시 본체에서 진동이 발생하여 대상자가 다시 복부수축을 하도록 되먹임을 제공한다. 이후 대상자가 복부근육을 수축하고 허리둘레 길이가 기준값 이 하로 감소하면 진동은 멈추게 된다. 대상자마다 허리둘레의 변 화가 차이가 있기 때문에 길이변화에 너무 민감하거나 둔감할 경우 재조정하였다. 이러한 되먹임은 대상자가 다시 복근의 수 축을 유지하도록 하며 8주간, 주 5 회, 일일 $30 \mathrm{~min}$ 실시하였다. 대조군도 일일 $60 \mathrm{~min}$, 주 3 회, 8 주 동안 필라테스 운동을 실시 하였다. 또한 일상생활 중 복근수축의 중요성을 반복적으로 교 육하였다.

2) 필라테스

필라테스는 실험군과 대조군 모두 8주간 주 3회, 1 회당 60 min을 실시하였다(Table 2), 운동 프로그램은 미국 뉴욕 PIA (pilates academy international)의 공식프로그램을 기반으로 연구 대상자들의 기능적 능력을 고려하여 동작을 선택하였다 (Kim \& Kim, 2012).

Table 2. The pilates exercise program

\begin{tabular}{|c|c|c|}
\hline Item & Exercise program & Times \\
\hline Warm-up (10 min) & $\begin{array}{l}\text { 1. Breathing } \\
\text { 2. Imprint } \\
\text { 3. Coccyx curl } \\
\text { 4. Shoulder bridge } \\
\text { 5. Curl up }\end{array}$ & $\begin{array}{l}5 \text { sets } \\
5 \text { sets } \\
5 \text { sets } \\
5 \text { sets } \\
5 \text { sets } \times 3 \text { sets }\end{array}$ \\
\hline & $\begin{array}{l}\text { 1. The hundred } \\
\text { 2. The roll-up } \\
\text { 3. Single leg circles } \\
\text { 4. Rolling like a ball } \\
\text { 5. Single leg stretch }\end{array}$ & $\begin{array}{l}10 \text { reps } \times 10 \text { sets } \\
6 \text { reps } \times 2 \text { sets } \\
6 \text { reps } \times 2 \text { sets } \\
6 \text { reps } \times 2 \text { sets } \\
6 \text { reps } \times 3 \text { sets }\end{array}$ \\
\hline Main exercise (40 min) & $\begin{array}{l}\text { 1. Double leg stretch } \\
\text { 2. Spin stretch forward } \\
\text { 3. Crisscross } \\
\text { 4. Open-leg rocker } \\
\text { 5. Swan dive } \\
\text { 6. Spin twist }\end{array}$ & $\begin{array}{l}6 \text { reps } \times 3 \text { sets } \\
6 \text { reps } \times 3 \text { sets } \\
6 \text { reps } \times 2 \text { sets } \\
6 \text { reps } \times 2 \text { sets } \\
8 \text { reps } \\
6 \text { reps } \times 2 \text { sets }\end{array}$ \\
\hline & $\begin{array}{l}\text { 1. The side kick series } \\
\text { 2. Teaser } \\
\text { 3. Swimming } \\
\text { 4. The seal } \\
\text { 5. The saw } \\
\text { 6. Push up }\end{array}$ & $\begin{array}{l}8 \text { reps } \times 2 \text { sets } \\
8 \text { reps } \\
6 \text { reps } \times 2 \text { sets } \\
8 \text { reps } \\
6 \text { reps } \times 2 \text { sets } \\
5 \text { reps }\end{array}$ \\
\hline Cool-down (10 min) & $\begin{array}{l}\text { 1. Head nods } \\
\text { 2. Scapula } \\
\text { 3. Hip rolls } \\
\text { 4. Breast stroke } \\
\text { 5. Cat stretch } \\
\text { 6. Shell stretch } \\
\text { 7. Piriformis } \\
\text { 8. Child pose }\end{array}$ & $\begin{array}{l}8 \text { reps } \\
8 \text { reps } \times 2 \text { sets } \\
4 \text { reps } \\
6 \text { reps } \times 2 \text { sets } \\
6 \text { reps } \times 2 \text { sets } \\
6 \text { reps } \times 2 \text { sets } \\
6 \text { reps } \times 2 \text { sets } \\
6 \text { reps } \times 2 \text { sets }\end{array}$ \\
\hline
\end{tabular}




\section{3. 측정 방법}

\section{1) 신체조성 검사}

체지방률을 측정하기 위해 다주파수 부위별 임피던스 측정기 가 사용되었다. 생체전기 임피던스법은 인체에 다주파수를 동시 에 흘려보내 각각의 주파수에 해당하는 임피던스 값만 측정하는 기술이다(Janssen et al., 2000). 연구대상자는 개인정보를 입 력한 후 체성분 분석기에 올라서서 손과 발을 전극에 대고 편안 하게 선 자세로 측정하였다. 체성분 분석기를 통한 조사항목 중 체중 $(\mathrm{kg})$, 체질량지수 $\left(\mathrm{kg} / \mathrm{m}^{2}\right)$, 체지방률 $(\%)$, 복부지방률 $(\%)$ 을 산출하였다. 측정은 실험 전과 후에 각각 실시하였다.

\section{2) 몸통 안정성 검사}

몸통의 안정성을 측정하기 위해 코어 근지구력 검사를 실시하 였다. 측정은 네 가지 자세로 몸통신전, 몸통굴곡, 양측 사이드 브릿지를 실시하였다. 첫 번째는 신전근지구력 검사로 대상자 는 시험대에 엎드린 자세에서 발목과 무릎을 벨트로 고정하고, 상반신은 시험대의 가장자리에 위치하였다. 시험대의 높이보다 $25 \mathrm{~cm}$ 아래에 보조 베드를 위치하여 검사하기 전 상체를 올려 놓았다. 측정 시 대상자는 양손을 반대쪽 어깨에 대고 상체를 들 어 올려 바닥과 수평이 되도록 유지하였다. 시간 측정은 대상자 의 상체가 수평 위치에서 보조 베드에 닿을 때까지 초 단위로 기 록하였다. 두 번째, 굴곡근지구력 검사는 대상자가 시험대 위에 앉아 $60^{\circ}$ 의 각도의 웨지에 상체를 기대어 시작자세를 취하였다. 대상자의 발목은 벨트로 고정하였으며 무릎과 고관절 모두 $90^{\circ}$ 로 구부린 자세에서 양손을 반대쪽 어깨에 대고 시작 자세를 취 하였다. 측정 시 대상자는 웨지로부터 $10 \mathrm{~cm}$ 정도 뗀 상태를 유 지하도록 지시하였다. 시간 측정은 대상자의 상체가 웨지에 닿 을 때까지 측정하였다. 세 번째, 사이드 브릿지 검사는 다리를
편 상태에서 옆으로 눕고 한 쪽 팔꿈치를 세워 시작자세를 취하 였다. 측정 시 대상자는 매트에서 엉덩이를 들어 올려 체중이 팔 꿈치와 발에 위치하고 몸 전체가 직선을 유지하도록 하였다. 시 간 측정은 엉덩이가 매트에 닿을 때까지 측정하였으며 양측 모 두 실시하였다. 모든 측정은 실험 전과 후에 각각 실시하였다.

\section{4. 분석 방법}

본 연구에서 측정된 자료는 윈도우용 SPSS ver. 21.0 (IBM, USA)을 이용하여 분석하였다. 대상자의 일반적 특성은 기술통 계를 이용하여 평균과 표준편차를 계산하고, 정규성 검정을 위 해 Shapiro-Wilk test를 이용하였다. 허리둘레 감지기 유무에 따른 실험 전과 후의 변화 양상을 비교하기 위하여 대응표본 $t$ 검정을 실시하였다. 두 군에서 측정시점 간의 차이를 알아보기 위해 독립표본 $t$ 검정을 사용하였다. 모든 통계학적 유의수준은 0.05 로 하였다.

\section{Results and Discussion}

허리둘레변화 감지의 실시간 생체되먹임 제공 유무에 따라 신체조성의 변화를 분석하여 다음과 같은 결과를 얻었다(Table 3). 실험군은 실험 후 체중, 체질량지수, 체지방률, 복부지방률 모두에서 유의한 감소를 보였다( $p<0.05)$. 대조군에서는 실험 후 모든 항목에서 유의한 차이가 없었다.

실험 전 평가에서 두 군간 모든 항목에서 유의한 차이가 없었 다. 실험 후 평가에서 두 군간 체지방률과 복부지방률은 유의하 게 감소되었다( $p<0.05)$. 하지만 체중과 체질량지수는 유의한 차 이가 없었다.

Table 3. Body composition before and after pilates between the experimental and control groups

\begin{tabular}{llccc}
\hline & & $\begin{array}{c}\text { Experimental group } \\
\left(\mathrm{n}_{1}=16\right)\end{array}$ & $\begin{array}{c}\text { Control group } \\
\left(\mathrm{n}_{2}=15\right)\end{array}$ & $t$ \\
Weight $(\mathrm{kg})$ & Pre & $57.04 \pm 8.57^{\mathrm{a}}$ & $58.54 \pm 8.56$ & -0.48 \\
& Post & $55.74 \pm 8.10$ & $58.44 \pm 8.72$ & -0.89 \\
& $t$ & $2.818^{*}$ & 0.450 & -0.49 \\
$\mathrm{BMI}^{\mathrm{b}}\left(\mathrm{kg} / \mathrm{m}^{2}\right)$ & Pre & $21.33 \pm 2.91$ & $21.82 \pm 2.42$ & -1.01 \\
& Post & $20.87 \pm 2.57$ & $21.79 \pm 2.45$ & 0.308 \\
$\operatorname{PBF}^{\mathrm{c}}(\%)$ & $t$ & $2.484^{*}$ & $30.68 \pm 5.33$ & -0.01 \\
& Pre & $30.69 \pm 3.11$ & $30.25 \pm 4.84$ & $-2.19^{*}$ \\
$\mathrm{WHR}^{\mathrm{d}}(\%)$ & Post & $26.95 \pm 3.45$ & 1.048 & -0.18 \\
& $t$ & $5.576^{* *}$ & $0.86 \pm 0.03$ & $-2.05^{*}$ \\
\hline
\end{tabular}

${ }^{a}$ mean \pm standard deviation; ${ }^{b}$ body mass index; ${ }^{\circ}$ body fat percentage; ${ }^{d}$ waist-hip ratio. ${ }^{*} p<0.05 ;{ }^{* *} p<0.01$. 
몸통 안정성을 평가하기 위한 코어 근지구력 검사는 네 가지 자세에서 다음과 같은 결과를 얻었다(Table 4). 실험군은 실험 후 몸통신전, 몸통굴곡, 좌측 사이드 브릿지에서 유의한 증가를 보였다 $(p<0.05)$. 하지만, 우측 사이드 브릿지에서는 유의한 차 이가 없었다. 대조군에서는 실험 후 좌측 사이드 브릿지에서 유 의한 증가를 보였으나 $(p<0.05)$ 몸통신전, 몸통굴곡 그리고 우측 사이드 브릿지에서는 유의한 차이가 없었다.

실험 전 평가에서 두 군간 몸통신전, 몸통굴곡, 좌측 사이드 브릿지, 우측 사이드 브릿지 모두 유의한 차이가 없었다. 실험 후 평가에서도 모든 항목에서 유의한 차이가 없었다.

필라테스는 신체의 국소근육을 활성화하여 근육의 균형을 개 선하고 복근과 몸통 안정성에 관여하는 근육을 강화시켜 탄탄 하고 아름다운 몸매를 만들어준다(Yu \& Kim, 2010). 복근과 허리주변 근육을 효과적으로 사용하기 위해선 대근육(global muscles)보다 국소근육을 먼저 수축하고 지속적으로 사용해야 한다(Ferreira et al., 2006; Thompson et al., 2006). 그리고 허리주변에 있는 굴곡근과 신전근의 동시수축은 복강내압 상승 을 통해 요추의 안정성을 증가시킨다(Arokoski et al., 2001). 이러한 국소근육의 활성과 허리주변 근육의 동시수축을 증가 시키기 위해 선택적 운동조절과 특별한 훈련 방법이 필요하다 (Hodges et al., 1997; Tsao et al., 2011). 본 연구에서는 다양 한 훈련 방법 중 효과가 증명된 배꼽당기기 방법을 대상자에게 교육하였다(Urquhart et al., 2005).

치료적 관점에서 효과적인 복근 수축과 훈련을 위해 초음파나 근전도 신호 그리고 동작센서 등의 생체되먹임을 이용하였지만 (Kent et al., 2015), 일반인들의 사용은 시공간 및 고가의 장비 로 제한적이다. 일반인들이 몸통 안정화를 위해 요추부 근육의 수축이 중요하다는 것을 알고 있음에도 운동 시를 제외한 일상
생활 중에는 복근 수축을 거의 하지 않는다. 따라서 일상생활 중 복근수축을 유도하는 되먹임이 필요하였다. 이에 일상생활 중 복근수축을 유도하는 허리둘레 감지기를 이용하였다. 허리둘레 감지기는 기준값보다 더 늘어날 경우 본체에 있는 길이 변화 센 서를 통해 감지하여 진동을 발생시킨다. 다시 복근을 수축하여 허리둘레를 감소시키면 진동은 없어진다. 따라서 본 연구는 필 라테스 참여자에게 추가적으로 일상생활에서 허리둘레변화 감 지의 실시간 되먹임을 이용한 의도적인 복근수축을 제공하였다.

신체조성의 측정은 체성분 분석기를 이용하였다. 신체조성은 주로 지방과 이외 조직으로 구분하여 체중에서 신체 지방량이 차지하는 비율(\%)로 사용된다. 이러한 신체조성은 개인의 영양 과 건강 상태를 평가하는데 사용된다(Kim, 2011). 체성분 분석 기의 급간내 상관계수(intraclass correlation coefficient; ICC) 는 0.92로 아주 높은 수준의 신뢰도를 보였다(Dolezal et al., 2013)

몸통 안정성을 평가하기 위해 코어 근지구력 검사를 실시하였 다. 몸통 안정성을 평가하기 위해 다양하게 접근되고 있으며 근 력검사, 근지구력 검사, 유연성 검사, 운동조절 검사, 기능적 검 사 등으로 이루어져 있다(Panjabi, 1992; Shamsi et al., 2015). 본 연구에서는 McGill et al. (1999)이 제시한 몸통신전, 몸통굴 곡, 양측의 사이드 브릿지를 이용한 네 가지 측정자세를 실시하 였다. 이 측정 방법은 급간내 상관계수가 $0.66-0.96$ 로 중등도 부터 매우 높은 수준까지의 신뢰도를 보였다(Waldhelm \& Li, 2012).

본 연구는 일상생활 중 실시간 되먹임을 이용한 의도적인 복 근 수축의 효과를 알아보기 위해 신체조성과 몸통 안정성 검사 를 실시하였다. 신체조성 검사에서 실험군은 체중, 체질량지수, 체지방률 그리고 복부지방률 모든 항목에서 유의한 감소를 보여

Table 4. Core stability score before and after pilates between the experimental and control groups

\begin{tabular}{|c|c|c|c|c|}
\hline & & $\begin{array}{l}\text { Experimental group } \\
\qquad\left(n_{1}=16\right)\end{array}$ & $\begin{array}{c}\text { Control group } \\
\left(n_{2}=15\right)\end{array}$ & $t$ \\
\hline \multirow{3}{*}{ Trunk flexion (s) } & Pre & $37.62 \pm 9.23^{\mathrm{a}}$ & $35.80 \pm 6.61$ & 0.62 \\
\hline & Post & $41.68 \pm 8.37$ & $38.20 \pm 4.98$ & 1.39 \\
\hline & $t$ & $-3.546^{*}$ & -1.718 & \\
\hline \multirow{3}{*}{ Trunk extension (s) } & Pre & $45.00 \pm 8.10$ & $45.93 \pm 7.21$ & -0.33 \\
\hline & Post & $49.06 \pm 8.09$ & $48.06 \pm 9.25$ & 0.31 \\
\hline & $t$ & $-3.470^{*}$ & -1.554 & \\
\hline \multirow{3}{*}{ Left side bridge (s) } & Pre & $24.42 \pm 6.33$ & $23.27 \pm 4.29$ & 0.59 \\
\hline & Post & $27.07 \pm 5.90$ & $25.59 \pm 3.34$ & 0.85 \\
\hline & $t$ & $-3.539^{*}$ & $-2.545^{*}$ & \\
\hline \multirow{3}{*}{ Right side bridge (s) } & Pre & $26.70 \pm 8.13$ & $23.98 \pm 4.43$ & 1.14 \\
\hline & Post & $28.15 \pm 5.73$ & $25.70 \pm 3.43$ & 1.42 \\
\hline & $t$ & -1.310 & -1.421 & \\
\hline
\end{tabular}

${ }^{a}$ mean \pm standard deviation; ${ }^{*} p<0.05$. 
주었다 $(p<0.05)$. Park \& Lee (2009)는 여대생에게 필라테스 운 동이 체중, 체지방량, 복부지방률 그리고 체질량지수가 감소하 는 것으로 보고하였으며, Kwon \& Kim (2010)의 연구에는 필라 테스 운동과 유산소운동을 함께 적용하였을 때 체중, 체지방률, 체질량지수가 유의하게 감소되었다고 하였다. 이러한 결과는 본 연구와 유사하다고 할 수 있다. 하지만, Shim et al. (2011)은 비 만 남성에게 필라테스 운동을 적용한 후 체중과 체질량지수, 복 부지방률에 유의한 감소가 없었다. 이는 성별 및 운동 프로그램 의 기간 및 강도 그리고 추가적인 운동 제공이 다르기 때문인 것 으로 생각된다. 실험 후 두 군간 평가에서 체중과 체질량지수는 유의한 차이가 없었으나 체지방률과 복부지방률은 실험군이 대 조군보다 유의하게 감소를 보여주었다. 이러한 결과는 필라테스 운동과 의도적인 복근수축을 함께 실시할 경우 더 효과적임을 의미한다.

몸통 안정성 검사에서 실험군은 우측 사이드 브릿지를 제외 한 몸통신전, 몸통굴곡, 좌측 사이드 브릿지에서 유의한 증가를 보였으며 $(p<0.05)$, 대조군에서는 실험 후 좌측 사이드 브릿지에 서만 유의한 증가를 보였다 $(p<0.05)$. 통계적으로 유의한 차이를 보이지 못하였지만 두 군 모두 실험 후 자세 유지 시간이 증가 하였으며 이러한 결과는 필라테스 운동이 몸통 안정성에 효과가 있음을 의미한다. Yu \& Lee (2012)의 연구에서는 8주간 필라테 스를 이용한 코어 안정화 운동이 하지의 근력과 자세 안전성 평 가에서 유의한 증가를 보여주었고 본 연구의 결과와 유사하였 다.

본 연구는 필라테스 참여자에게 실시간 되먹임을 통한 의도적 인 복근 수축을 제공하여 근육을 더 활성화 시켰다. 그 결과 필 라테스만 실시한 경우보다 더 효과적으로 체지방률과 복부지방 률이 감소하였으며 몸통 안정성은 증가됨을 보여주었다. 이는 아름다움을 위한 미용의 측면과 건강 증진을 위한 측면 모두에 효과가 있음을 의미한다. 추후 연구에서는 여성뿐만 아니라 남 성이나 중장년층과 같이 대상자를 세분화하고 코어근육의 근활 성도를 측정하여 기존 몸통 안정화 운동과의 비교 연구가 필요 할 것이다.

\section{Conclusion}

본 연구에서 일상생활 중 실시간 되먹임을 통한 의도적인 복 근수축은 몸통의 안정성을 향상시키고 체지방률과 복부지방률 등의 신체조성에 긍정적인 효과를 주었다. 필라테스 운동과 일 상생활 중 되먹임 제공은 운동학습을 유도하여 복부 근육이 장 시간, 저강도의 수축이 되도록 하였다. 이를 통해 복부에서 에 너지를 사용하며 근육의 탄력 증가와 지방량 감소에 영향을 주 었을 것으로 사료된다. 필라테스 운동과 함께 의도적인 복근 수
축이 제공된다면 아름다운 몸매를 위한 미용적인 면과 몸통 안 정화를 통한 건강적인 면 모두 효과적일 것이다.

\section{References}

Arokoski JP, Valta T, Airaksinen O, Kankaanpää M. Back and abdominal muscle function during stabilization exercises. Archives of Physical Medicine and Rehabilitation, 82: 1089-1098, 2001.

Beith ID, Synnott RE, Newman SA. Abdominal muscle activity during the abdominal hollowing manoeuvre in the four point kneeling and prone positions. Manual Therapy, 6: 82-87, 2001.

Dayan E, Cohen LG. Neuroplasticity subserving motor skill learning. Neuron, 72: 443-454, 2011.

Dolezal BA, Lau MJ, Abrazado M, Storer TW, Cooper CB. Validity of two commercial grade bioelectrical impedance analyzers for measurement of body fat percentage. Journal of Exercise Physiology Online, 16: 74-83, 2013.

Dozza M, Chiari L, Peterka RJ, Wall C, Horak FB. What is the most effective type of audio-biofeedback for postural motor learning? Gait \& Posture, 34: 313-319, 2011.

Ferreira PH, Ferreira ML, Maher CG, Herbert RD, Refshauge K. Specific stabilisation exercise for spinal and pelvic pain: a systematic review. Australian Journal of Physiotherapy, 52: 79-88, 2006.

Hodges PW, Gandevia SC, Richardson CA. Contractions of specific abdominal muscles in postural tasks are affected by respiratory maneuvers. Journal of Applied Physiology, 83: 753-760, 1997.

Janssen I, Heymsfield SB, Baumgartner RN, Ross R. Estimation of skeletal muscle mass by bioelectrical impedance analysis. Journal of Applied Physiology, 89: 465-471, 2000.

Jung DE, Kim K, Lee SK. Comparison of muscle activities using a pressure biofeedback unit during abdominal muscle training performed by normal adults in the standing and supine positions. Journal of Physical Therapy Science, 26: 191-193, 2014.

Kent P, Laird R, Haines T. The effect of changing movement and posture using motion-sensor biofeedback, versus guidelines-based care, on the clinical outcomes of people with sub-acute or chronic low back pain-a 
multicentre, cluster-randomised, placebo-controlled, pilot trial. BMC Musculoskeletal Disorders, 16: 131-149, 2015.

Kim NJ. Effects of elastic band and pilates exercise on BMD and body composition in office working women. Journal of Korean Physical Education Association for Girls and Woman, 25: 13-22, 2011.

Kim YH, Kim EJ. Effects of participation in pilates exercise on obesity degree, blood lipid level, and self-esteem in obese female university students. The Korean Journal of Dance Research, 12: 73-81, 2012.

KOSIS (National Health Insurance Service, Statistics on the metabolic risk factors by age and gender), 2017.01.31.

Kwon HJ, Kim NJ. Effects of aerobic exercise and pilates exercise on body composition and blood variables in postmenopausal obese women. The Korean Journal of Sports Science, 19: 679-688, 2010.

Lee SM, Yoo Jl. The relationship among exercise emotion, psychological well-being, and exercise satisfaction in pilates. Journal of Sport and Leisure Studies, 61: 421432, 2015.

McGill SM, Childs A, Liebenson C. Endurance times for low back stabilization exercises: clinical targets for testing and training from a normal database. Archives of Physical Medicine and Rehabilitation, 80: 941-944, 1999.

Mew R. Comparison of changes in abdominal muscle thickness between standing and crook lying during active abdominal hollowing using ultrasound imaging. Manual Therapy, 14: 690-695, 2009.

Nanhoe-Mahabier W, Allum JH, Pasman EP, Overeem S, Bloem BR. The effects of vibrotactile biofeedback training on trunk sway in Parkinson's disease patients. Parkinsonism and Related Disorders, 18: 1017-1021, 2012.

Neumann DA. Kinesiology of the musculoskeletal system: foundations for rehabilitation (2nd ed.). Mosby Elsevier, St. Louis, Missouri, pp155-167, 2010.

Panjabi MM. The stabilizing system of the spine. part I. function, dysfunction, adaptation, and enhancement. Journal of Spinal Disorders, 5: 383-389, 1992.

Park SS, Kwon JH. The effect of 12 weeks clture pysical eucation pilates exercise on the body composition and blood lipids, blood pressure in women college students.
The Korea Journal of Sports Science, 20: 1261-1269, 2011.

Park SS, Lee KJ. Effects of participation in pilates and dance sports exercise on body composition, muscular strength, flexibility of university students group. Journal of Korean Physical Education Association for Girls and Women, 23: 49-58, 2009.

Park SS, Park KH. Effect of pilates exercise on physical fitness and body composition of university students. Journal of Sport and Leisure Studies, 28: 301-309, 2006.

Segal NA, Hein J, Basford JR. The effects of pilates training on flexibility and body composition: an observational study. Archives of Physical Medicine and Rehabilitation, 85: 1977-1981, 2004.

Shamsi MB, Sarrafzadeh J, Jamshidi A. Comparing core stability and traditional trunk exercise on chronic low back pain patients using three functional lumbopelvic stability tests. Physiotherapy Theory and Practice, 31: 8998, 2015.

Shim SY, Kim YM, Ko SK. The effects of pilates on body composition, cholesterol, CRP and leptin in male obese adults. The Korean Journal of Sports Science, 20: 13011312, 2011.

Thompson JA, O'Sullivan PB, Briffa NK, Neumann P. Altered muscle activation patterns in symptomatic women during pelvic floor muscle contraction and Valsalva manouevre. Neurourology and Urodynamics, 25: 268-276, 2006.

Tsao H, Tucker KJ, Hodges PW. Changes in excitability of corticomotor inputs to the trunk muscles during experimentally-induced acute low back pain. Neuroscience, 181: 127-133, 2011.

Urquhart DM, Hodges PW, Allen TJ, Story IH. Abdominal muscle recruitment during a range of voluntary exercises. Manual Therapy, 10: 144-153, 2005.

Waldhelm A, Li L. Endurance tests are the most reliable core stability related measurements. Journal of Sport and Health Science, 1: 121-128, 2012.

Yu JH, Kim SJ. The effects of pilates on body fat rate, aerobic capacity and lower limb isokinetic strength. Asian Journal of Beauty and Cosmetology, 8: 81-90, 2010.

Yu JH, Lee GC. Effect of core stability training using pilates on lower extremity muscle strength and postural stability in healthy subjects. Isokinetics and Exercise Science, 20: 141-146, 2012. 


\section{국문초록}

\section{일상생활 중 실시간 되먹임을 동반한 의도적인 복근수축이 필라테스 참여자의 신체 조성과 몸통 안정성에 미치는 영향}

성재현 ${ }^{*}$, 김창범 ${ }^{2}$

${ }^{1}$ 대전웰니스병원 재활치료센터, 대전, 한국

${ }^{2}$ 대원대학교 물리치료학과, 충청북도 제천시, 한국

목적: 본 연구에서는 필라테스 운동 프로그램 참여자에게 의도적인 복근수축이 일상생활 중에도 가능하도록 실시간 되먹임을 제공 하여 신체조성과 몸통 안정성에 미치는 영향을 알아보았다. 방법: 대상자는 필라테스 참여자 중 실시간 되먹임을 제공한 16 명의 실 험군과 되먹임이 없는 15 명의 대조군으로 나누었다. 실험 전과 후 신체조성과 몸통 안정성 평가를 실시하였다. 실험군과 대조군 모 두 8주간 필라테스에 참여하였고 실험군만 허리둘레변화 감지의 실시간 되먹임을 추가 제공하였다. 결과: 신체조성 평가에서 실험 군은 실험 후 체중, 체질량지수, 체지방률, 복부지방률에서 유의한 감소를 보였으나 대조군은 실험 후 모든 항목에서 유의한 차이가 없었다. 두 군간 비교에서 실험군이 대조군보다 체지방률과 복부지방률이 유의하게 감소되었다. 몸통 안정성 평가에서 실험군은 실 험 후 몸통 신전, 몸통 굴곡, 좌측 사이드 브릿지에서 유의한 증가를 보였으며 대조군에서는 실험 후 좌측 사이드 브릿지에서 유의 한 증가를 보였다. 두 군간의 비교에서 모든 항목이 유의한 차이가 없었다. 결론: 실시간 되먹임을 동반한 의도적인 복근수축을 제 공받은 실험군에서 몸통의 안정성이 향상되었으며 체지방률, 복부지방률 등의 신체조성에 긍정적인 효과를 주었다. 필라테스 운동 과 함께 일상생활 중 의도적인 복근수축을 실시하면 아름다운 몸매를 위한 미용적인 면과 몸통 안정성을 통한 건강적인 면 모두에 효과적일 것이다.

핵심어: 필라테스, 실시간 되먹임, 신체조성, 몸통 안정성, 의도적인 복근수축

\section{참고문헌}

권호준, 김남정. 유산소 운동과 필라테스를 병행한 복합운동이 폐경기 비만 여성의 신체조성과 혈액성분에 미치는 영향. 한국 체육과학회지, 19: 679-688, 2010.

김남정. 탄력밴드와 필라테스의 복합운동이 사무직 직장여성의 골밀도와 신체구성에 미치는 영향. 한국여성체육학회지, $25:$ $13-22,2011$.

김윤희, 김은정. 필라테스 운동 참여가 비만 여대생의 비만도, 혈중지질 및 자아존중감에 미치는 영향. 한국무용학회지, 12 :

73-81, 2012.

박승순, 박경혜. Pilates 운동 참여가 대학생의 체력과 신체구성에 미치는 영향. 한국사회체육학회지, 28: 301-309, 2006. 박승순, 권정현. 12 주간의 교양체육 필라테스 수업이 여대생의 신체조성과 혈중지질 및 혈압에 미치는 영향. 한국체육과학회

지, 20: 1261-1269, 2011.

박승순, 이경주. 필라테스와 댄스스포츠 운동 참여가 대학생의 신체조성과 근력, 유연성에 미치는 영향. 한국여성체육학회지,

23: 49-58, 2009.

심소연, 김윤미, 고성경. 필라테스 운동이 비만남성의 신체구성, 콜레스테롤, $\mathrm{CRP}$ 및 렙틴에 미치는 영향. 한국체육과학회지,

20: 1301-1312, 2011.

유재호, 김성중. 필라테스가 체지방률, 유산소능력, 그리고 하지 등속성 근력에 미치는 영향. 아시안뷰티화장품학술지, 8: 81-90, 2010.

이승민, 유정인. 필라테스 참여자의 운동정서와 심리적 웰빙 및 운동만족의 관계. 한국사회체육학회지, 61: 421-432, 2015. KOSIS (국민건강보험공단, 연령별 성별 대사증후군 위험요인별 유병률), 2017.01.31. 


\section{中文摘要}

\section{日常生活中伴随实时反馈意向性腹部肌肉收缩对普拉提参与者身体成分和躯干 稳定性的的影响}

成在鉉 ${ }^{*}$, 金昌範 $^{2}$

${ }^{1}$ 大田wellness医院康复中心，大田，韩国

${ }^{2}$ 大元大学物理治廖学科，忠淸北道堤川市，韩国

目的: 普拉提参与者提供有意识的腹部肌肉收缩的实时反馈, 使他们能够在日常生活中练习这些收缩, 调查其身体成 分和躯干稳定性的影响。方法: 31名普拉提参与者被分为提供实时反馈的实验组 $(n=16)$ 和不提供实时反馈的对照组 $(n=15)$ 。在实验前后, 评估参与者的身体组成和躯干稳定性。两组都进行了8周的普拉提练习, 但只有实验组获得了 有关其腰围变化的实时反馈。结果: 在身体成分评估过程中，实验组的体重、体重指数、体脂百分比、腹部脂肪率均显 着下降, 而对照组在这些变量中没有显着差异。实验组与对照组相比, 体脂百分比和腹部脂肪率下降幅度明显大于对照 组。在躯干稳定性评价中, 实验组在实验后躯干伸展、躯干屈曲和左侧桥显示出统计学显着增加, 而对照组仅在左侧桥 显示出统计学显着增加。对于任何变量, 组间差异没有统计学显着性。结论: 实验组实施了有意识的腹肌收缩, 具有实时 反馈, 改善了躯干稳定性, 向体脂百分比和腹部脂肪率等身体组成给予积极效果。这些结果表明, 伴随普拉提锻炼的有 意识的腹部肌肉收缩为美丽身躯和通过改善躯干稳定性得到健康方面都具有效果。

关键词: 普拉提, 实时反馈, 身体组成, 身区干稳定性, 有意识的腹部肌肉收缩 